American Journal of Pharmaceutical Education 2018; 82 (4) Article 6257.

\title{
RESEARCH
}

\section{The Relationship Between Prior Experiences in Mathematics and Pharmacy School Success}

\author{
Kelly M. Conn, PhD, MPH, Christine Birnie, PhD, David McCaffrey, PhD, Jack Brown, PharmD, MS \\ Wegmans School of Pharmacy at St. John Fisher College, Rochester, New York \\ Submitted January 4, 2017; accepted March 10, 2017; published May 2018.
}

Objective. To assess students' pre-pharmacy math experiences, confidence in math ability, and relationship between experiences, confidence, and grades in math-based pharmacy courses.

Methods. A cross-sectional survey of first year to third year pharmacy students was conducted. Students reported type of pre-pharmacy math courses taken, when they were taken [high school (HS) vs. college] and year of HS and college graduation. Students rated their confidence in math ability using the previously validated 11-item Fogerty Math Confidence Scale (Cronbach alpha=0.92). Math grade point average (GPA), Pharmacy College Admission Test quantitative (PCAT quant) scores, and grades (calculations and kinetics) were obtained from transcripts and school records. Spearman correlation and multivariate linear regression were used to compare math experiences, confidence, and grades.

Results. There were 198 students who reported taking math courses 7.1 years since HS graduation and 2.9 years since their last schooling prior to pharmacy school. Students who took math courses with more time since HS/last schooling had lower calculations and kinetics grades. Students reporting having taken more HS math courses had better calculations grades. Students with higher math GPA, and PCAT quant scores also had higher calculations and kinetics grades. Greater confidence in math ability was associated with higher calculations grades. In multivariate regressions, PCAT quant scores and years since HS independently predicted calculations grades, and PCAT quant scores independently predicted kinetics grades.

Conclusion. The number of pre-pharmacy math courses and time elapsed since they were taken are important factors to consider when predicting a pharmacy student's success in math-based pharmacy school courses.

Keywords: math, pharmacy school grades, math confidence, pharmacy student

\section{INTRODUCTION}

Pharmacy schools' admissions committees are working to improve the selection of applicants who will be successful in their training as a pharmacist. ${ }^{1-7}$ These schools strive to understand key predictors of success based on the pre-professional pharmacy curriculum to guide incoming students on the foundational skills they will need to succeed in the PharmD program. ${ }^{1-7}$ Studies have used many factors to predict a student's pharmacy school performance, including grade point average (GPA), Pharmacy College Admissions Tests (PCAT), American College Testing (ACT) composite scores,

Corresponding Author: Kelly M. Conn, Department of Pharmacy Practice \& Administration, Wegmans School of Pharmacy, St. John Fisher College, 3690 East Ave., Rochester, NY 14618. Tel: 585-385-8159. E-mail: kconn@sjfc.edu and completion of a four-year college degree. ${ }^{2,5-10}$ Most have found that these factors predict pharmacy school performance, and when math/science GPAs were considered separately, high GPAs were found to be related to academic performance. ${ }^{3,4,6,7,9-11}$ However, it is important to understand how math skills, separate from science, predict success, especially in math-intensive coursework.

Although both basic and advanced mathematics are used in most pharmacy curricula, basic math skills predominate. Basic math skills have been shown in some studies to be related to academic performance among pharmacy students; however, different methods have been used to evaluate this relationship with varied results. ${ }^{6,11-13}$ Among these studies, few have provided a comprehensive assessment of pharmacy students' experiences with basic math, including other factors such as type of basic math courses, time since last schooling, etc. Confidence in math, which may or may not be directly related to basic 


\section{American Journal of Pharmaceutical Education 2018; 82 (4) Article 6257.}

math experiences, may also play an important role in predicting success in pharmacy school. These simple indicators could provide a richer understanding of how pharmacy schools can equip themselves to assist their students in achieving academic success.

Proficiency in pharmacy calculations is one important qualification of a skilled practicing pharmacist. The 2016 ACPE Standards for completion of the doctor of pharmacy degree indicate the importance of these calculation skills including "mastery of mathematical skills required to accurately prepare prescriptions that are therapeutically sound and safe for patient use." ${ }^{.14}$ Therefore, it is important to understand how pharmacy schools should consider pre-pharmacy courses, including mathematical backgrounds inclusive of basic math, in relation to a student's success in math-based courses.

This study was designed to evaluate basic math experiences of pharmacy students, their confidence in math, and their overall grades in math intensive courses. Objectives of this study were to describe pharmacy students' experiences with basic math courses, to measure and describe their confidence in math ability, and to assess the relationship between basic math and success in pharmacy school. The authors of this study hypothesized that having a stronger background in basic math (more basic math courses, fewer years since HS graduation, etc.) is related to better academic performance in math intensive courses.

\section{METHODS}

A population-based, cross-sectional study was conducted with P1, P2, and P3 students participating in a 4-year professional program. Students completed a survey to assess their experiences with basic math, their confidence in math ability, and the relationship to academic success. School records (including transcripts and pharmacy school grades) were used to assess the primary outcome. St. John Fisher College's Institutional Review Board approved all study procedures.

To be eligible, students needed to be currently enrolled in the PharmD program in either the P1, P2, or P3 year (2015-2016 academic school year). Students were informed by their instructor about the survey. An email was sent to all students in the class at the time that the instructor was verbally reviewing study details. The email included an overview of the study, a confidentiality clause, and a consent document that explained their active consent for participation via survey completion as well as permission to access transcripts and pharmacy school grades. Students who were not in attendance still received the email with full study details and a link to the survey. The survey was created and administered using the Qualtrics online survey platform (Qualtrics, Inc, Provo, UT). ${ }^{15}$ Qualtrics has the ability to generate individual, unique links for each student and to auto-generate reminder emails for surveys not completed. For this study, one reminder email was automatically sent to students who had not yet completed the survey. Students did not receive any compensation for completing the survey. Non-participation did not affect their grade, other course matters, or their standing within the school.

Students were asked about their prior experiences with math as far back as high school. They were presented with a list of possible basic math courses that could have been taken in high school (HS), HS-AP (advanced placement)/credit (college credit), or post-high school/college. The list of courses included pre-algebra, algebra I, algebra II, geometry, trigonometry, pre-calculus, calculus I, calculus II, probability/statistics, advanced statistics, mathematical modeling, and differential equations. They were also allowed to add their own response for any math course they completed that was not included in the list. Courses taken in HS (including AP courses) were tallied to create a total sum score of all HS math courses.

Confidence in math ability was assessed using a previously validated scale by Fogarty and colleagues. ${ }^{16}$ Students were asked to rate their confidence using the 11-item instrument. The scale was used previously in a population of students participating in a college-level mathematics course on linear algebra and calculus. ${ }^{16}$ The internal consistency/reliability for the scale was previously reported as $0.89 .{ }^{16}$ Questions were rated on a 5 -point Likert scale $(1=$ strongly agree, $2=$ agree, $3=$ neutral, $4=$ disagree, and $5=$ strongly disagree). Example questions include: "I have less trouble learning mathematics than other subjects," "I do not have a mathematical mind," and "I find mathematics problems interesting and challenging." After reverse scoring specific pre-determined items based on scale guidelines, confidence scores were obtained by calculating the mean of all eight items; higher scores indicate greater confidence in math.

Students' pre-pharmacy data and current grades in the PharmD program were collected from student records. Pre-pharmacy transcripts were obtained by accessing the Pharmacy College Application Service (PharmCAS) through the WebAdMIT portal. Pre-pharmacy data gathered included total math hours, math GPA, and PCAT quantitative scores (PCAT quant). Due to issues associated with the change from PharmAdMIT to WebAdMIT, transcript data related to math ability was not available for P3 students. The average PCAT quant score that included all PCAT attempts by the student was calculated. Pharmacy school academic records were also retrieved for both the pharmacy calculations course (calculations) and the kinetics unit of a pharmaceutics II course (kinetics); both courses are math intensive courses. 


\section{American Journal of Pharmaceutical Education 2018; 82 (4) Article 6257.}

Additional data such as student background and demographics including their current year of pharmacy study, high school (HS) graduation year, undergraduate degree [associate degree (AA) vs bachelor's degree (BA/ BS) vs pre-pharmacy requirements only], year of undergraduate degree completion, and graduate or technical schooling were collected. Student HS and college graduation dates were used to calculate the number of years since HS and years since last schooling (prior to PharmD enrollment).

This study is based on a convenience sample of students enrolled in the 2015-2016 P1-P3 cohorts. All statistical analyses were performed using IBM SPSS Statistics V24 for Windows (Armonk, NY). Descriptive statistics, including measures of central tendency, were used to assess normality of the data and to summarize the primary dependent and independent outcome variables. Spearman correlation and student's t-test were used to compare student grades with demographic characteristics and preprofessional pharmacy measurements (math GPA, PCAT quant) as well as student-reported math experiences and math confidence. Spearman correlation coefficient was used for analyses since some variables are ordinal and skewed; however, Pearson correlations were conducted for all data and the findings remain the same. Only Spearman correlation coefficients are reported for simplicity and clarity. Two multivariate linear regressions were used to predict academic performance outcomes (calculations and kinetics grades) that included covariates based on bivariate analyses.

\section{RESULTS}

Among the 248 students invited to participate in the survey, 210 responded (response rate: 85\%). Among those students, 10 did not answer all questions, and two had unresolvable issues with their student IDs and, as such, the study investigators were unable to match their surveys with transcript and classroom data. Therefore, 12 were excluded from analyses and 198 students were included in the final analyses.

Among the 198 students included in this study, 127 were female (64\%) and 71 were in their P1 year (36\%), 65 in their P2 year (34\%) and 62 in their P3 year (31\%). Prior to pharmacy school, students reported having completed undergraduate degrees or requirements as follows: bachelor's degree $(45.5 \%)$, associate's degree $(13.1 \%)$, only pre-pharmacy requirements $(44.4 \%)$. Nearly all students completed the traditional algebra, geometry, and trigonometry HS series in their HS years, and many completed advanced courses (calculus and statistics) in their post HS/college years (Table 1). On average, students completed HS over 7 years prior to starting pharmacy school
Table 1. Number of Students Taking Specific Mathematics Courses

\begin{tabular}{lcccc}
\hline & & & & $\begin{array}{c}\text { Total } \\
\text { Mathematics } \\
\text { Courses }\end{array}$ \\
& HS & HS (AP) & $\begin{array}{c}\text { Post-HS } \\
\text { (College) }\end{array}$ & $\begin{array}{c}\text { (HS, HS (AP)+ } \\
\text { Post-HS) }\end{array}$ \\
\hline Pre-Algebra & 172 & 4 & 12 & 188 \\
Algebra I & 179 & 4 & 13 & 196 \\
Algebra II & 179 & 5 & 14 & 198 \\
Geometry & 186 & 5 & 6 & 197 \\
Trigonometry & 181 & 7 & 11 & 199 \\
Pre-Calculus & 145 & 26 & 39 & 210 \\
Calculus I & 36 & 69 & 128 & 233 \\
Calculus II & 14 & 25 & 91 & 130 \\
Probability/ & 25 & 21 & 169 & 215 \\
$\quad$ Statistics & & & & 36 \\
Advanced & 4 & 6 & 26 & 19 \\
$\quad$ Statistics & & & & 34 \\
Mathematical & 7 & 1 & 11 & \\
$\quad$ Modeling & & & & \\
Differential & 5 & 5 & 24 & \\
$\quad$ Equations & & & & \\
\hline
\end{tabular}

and had nearly 3 years between their last schooling and pharmacy school (Table 2).

Students reported an overall GPA of $3.1(\mathrm{SD}=1.1)$ and PCAT quant of $405.4(\mathrm{SD}=15.6)$. Table 3 shows the students' pre-pharmacy math experiences. Students reported taking more HS math courses prior to pharmacy school, compared to college math courses pre-pharmacy. Algebra courses accounted for approximately one-third of all pre-pharmacy courses taken prior to entering pharmacy school. A previously validated 11-item mathematics confidence scale was used to rate the students' confidence in math. ${ }^{16}$ Because this scale was used in a non-pharmacy population of students attending college, and never with pharmacy students, reliability testing was undertaken. Among our sample, the scale displayed acceptable reliability (Cronbach's alpha $=0.92$ ). The mean (SD) math confidence score was 3.7 (.76) indicating a high degree of confidence among this population. Additionally, greater than $80 \%$ of the students had confidence scores higher than the mean and more confidence in math

Table 2. Number of Years Between Completion of Educational Milestones and the Start of Pharmacy School

\begin{tabular}{lccccc}
\hline & Mean & SD & Q1 & Q3 & IQR \\
\hline Years since HS graduation & 7.1 & 3.9 & 4.0 & 9.0 & 5.0 \\
$\begin{array}{l}\text { Years between latest schooling } \\
\text { and pharmacy school }\end{array}$ & 2.9 & 2.1 & 1.0 & 4.0 & 3.0 \\
\hline
\end{tabular}




\section{American Journal of Pharmaceutical Education 2018; 82 (4) Article 6257.}

Table 3. Pre-pharmacy Math Experiences; Student

Self-Report Data

\begin{tabular}{lc}
\hline & Mean (SD) Range \\
\hline $\begin{array}{l}\text { Total no. of mathematics courses } \\
\text { taken prior to pharmacy school }\end{array}$ & $9.5(2.4) 1-24$ \\
$\begin{array}{l}\text { Total no. HS mathematics courses } \\
\quad \text { including AP) prior to pharmacy }\end{array}$ & $6.7(2.1) 0-18$ \\
$\quad$ school & \\
$\begin{array}{l}\text { Total no. college mathematics courses } \\
\text { taken prior to pharmacy school }\end{array}$ & $3.0(1.9) 1-10$ \\
$\begin{array}{l}\text { Total no. algebra courses taken } \\
\text { pre-pharmacy }\end{array}$ & $3.0(0.8) 0-7$ \\
\hline
\end{tabular}

ability was associated with higher calculations grades $(\rho=.259, p<.001)$.

Overall, the average calculations grade was 88.0 (range: $60.8-100.0$, SD: 7.56) and the average kinetics grade was 87.3 (range: 56.0-99.0, SD: 7.32) (Table 4). In bivariate analyses, time since high school and time since last schooling were inversely associated with grades in each of the pharmacy school courses (calculations and kinetics) (Table 4). Specifically, students with more time since graduating high school or more time since their last schooling had lower grades in calculations and kinetics. Additionally, there was also a relationship between math GPA and PCAT quant scores; students with higher math GPA and higher PCAT quant scores had higher calculations and kinetics grades. Students reporting greater number of HS math courses and college math courses prior to pharmacy school had better calculations grades $(\rho=.290$, $p<.001$ and $\rho=.234, p=.001$, respectively).

Two multivariate linear regressions were conducted predicting calculations grades and kinetics grades each controlling for the following covariates: math GPA, PCAT quant, years since HS, total number of HS math courses (including AP), and math confidence (Table 5). In a multivariate regression model predicting calculations grades (model $r=0.49$ ), PCAT quant scores and years since HS independently predicted grades. PCAT quant scores more strongly predicted calculations grades with a higher standardized beta; however, years since HS was still significantly associated with calculations grades even after controlling for all other covariates. In a model predicting kinetics grades (model $\mathrm{r}=0.32$ ), PCAT quant scores independently predicted grades, however, years since HS did not remain statistically significant in this model.

\section{DISCUSSION}

This study was designed to better understand basic math skills and confidence in math ability among pharmacy students. Specifically, students' experiences with high school math reported and compared with grades in math-intensive pharmacy school courses. Overall, students in this study completed an average of three algebra courses and seven basic math courses prior to enrollment. Moreover, many had some level of an advanced statistics course beyond those of HS and general college requirements.

In this study, the high school time period was very important for students; including how many math courses they took, and how long it had been since they graduated. Interestingly, more years since high school graduation was an important predictor of poor academic performance in the calculations course. These findings may be due to the high concentration of math courses taken during the HS years, the courses taken in HS are primarily basic math courses, or both. Interestingly, years since HS only predicted calculations grades and not kinetics grades. This may be due to the fact that the calculations course is taken earlier in the PharmD program and thus is likely more affected by the prior HS math experiences and time since HS. McCall and colleagues found that advanced mathematics college level coursework beyond required prerequisites do not predict academic performance of pharmacy

Table 4. Spearman's Correlation Coefficient (rho) Between Course Grade and Various Educational Achievements

\begin{tabular}{|c|c|c|c|c|}
\hline & Calculations Grade & $p$ & Kinetics Grade & $p$ \\
\hline \multicolumn{5}{|l|}{ Years since schooling } \\
\hline Years since HS graduation & $\rho=-0.21$ & .004 & $\rho=-0.17$ & .02 \\
\hline \multicolumn{5}{|l|}{ Transcript data } \\
\hline Math GPA & $\rho=0.23$ & .007 & $\rho=0.28$ & .001 \\
\hline \multicolumn{5}{|l|}{ Confidence in math } \\
\hline Fogarty Mathematics Confidence Scale & $\rho=0.26$ & $<.001$ & $\rho=0.09$ & .23 \\
\hline
\end{tabular}




\section{American Journal of Pharmaceutical Education 2018; 82 (4) Article 6257.}

Table 5. Linear Regression Models Predicting Calculations and Kinetics Grades

\begin{tabular}{lccccc}
\hline & Calculations & & \multicolumn{2}{c}{ Kinetics } \\
& Standardized Beta & $\boldsymbol{p}$ & Standardized Beta & $\boldsymbol{p}$ \\
\hline Math GPA & 0.14 & .08 & 0.11 & .20 \\
Average PCAT Quant Score & 0.32 & $<.001$ & 0.20 & .03 \\
Years since HS Graduation & -0.18 & .02 & -0.09 & .31 \\
Total no. of HS math courses (including AP) prior to pharmacy school & 0.08 & .33 & -0.004 & .97 \\
Fogarty Mathematics Confidence Scale & 0.13 & .12 & 0.14 & .13 \\
\hline
\end{tabular}

students. ${ }^{6}$ Therefore, if the primary HS courses are important, it is understandable that more time out of high school is correlated with poorer performance in pharmacy school, as found in this study.

Few schools use prior math experiences, or math GPA alone, as an admissions requirement. ${ }^{1}$ Boyce and colleagues provided recommendations for two preprofessional curricular models for PharmD programs to use in their evaluation of requirements for admission. ${ }^{1}$ While college courses such as statistics were included, basic math courses such as algebra, were not. The use of statistical analyses as a foundation for these curricular models is valuable; however, inclusion of basic mathematics from the HS years would have provided further perspective in the formulation of these models. The recommendations based on these models are similar to our institution admission criteria as well as the students comprised in this sample. This includes the requirement of statistics and calculus needed for acceptance into our program; there is no requirement for basic math among our students and the sample of students in this study. Also, in a 2007 survey of deans of US colleges and schools of pharmacy, statistics was a preference for core science courses as a pre-professional requirement but basic math was not.

This study also measured student confidence in their math ability using a previously validated scale. Although a significant association between student confidence in math and their pharmacy school grades was found, these findings were not sustained in a model that included more predictive factors such as PCAT quant and years since high school. To the authors' knowledge, this is the first study that assessed confidence in math, specifically among pharmacy students. Further studies should be conducted to understand the role of confidence, together with prior math experiences, in best predicting pharmacy school academic performance.

Limitations of this study include self-report of prior math experiences, and limited access to transcripts and grades for a subset of students. Students were required to recall courses taken throughout high school and after; however, for some students, this could have been over
$10+$ years of recall. To help with recall, an extensive list of all typical high school math courses was provided. Because many of the more advanced courses taken in high school, are also typical college level courses, we were able to compile an adequate list of courses that students may have taken throughout their pre-pharmacy years. Transcripts and student grades for this study were not provided for all cases; however, this was only for one of the three cohorts and therefore, this missing data should not affect the primary findings of this study.

\section{CONCLUSION}

Findings from this study indicate a need for further exploration of high school factors contributing to pharmacy school academic success, including years since graduation, types of math courses taken, quantity of math hours in high school, and academic performance during basic math courses. High school is an important part of growth and learning, especially due to the high concentration of foundational math courses taken during this time. Pharmacy students take math intensive courses throughout their training, and may be substantially affected by their high school math preparation. Knowing that this is the case may lead to the development of effective remediation programs aimed at avoiding academic difficulties related to a student's math abilities or the alteration of admission formulae to place an appropriate weight on math ability.

\section{REFERENCES}

1. Boyce EG, Lawson LA. Preprofessional curriculum in preparation for doctor of pharmacy educational programs. Am J Pharm Edu. 2009;73(8):Article 155.

2. Broedel-Zaugg K, Buring SM, Shankar N, et al. Academic pharmacy administrators' perceptions of core requirements for entry into professional pharmacy programs. Am J Pharm Edu. 2008;72(3): Article 52.

3. Chisholm MA, Cobb HH III, Kotzan JA. Significant factors for predicting academic success of first-year pharmacy students. Am J Pharm Edu. 1995;59:364-370.

4. Chisholm MA, Cobb III HH, DiPiro JT, Lauthenschlager GJ. Development and validation of a model that predicts the academic ranking of first-year pharmacy students. Am J Pharm Educ. 1999;63(4):388-394. 


\section{American Journal of Pharmaceutical Education 2018; 82 (4) Article 6257.}

5. Houglum JE, Aparasu RR, Delfinis TM. Predictors of academic success and failure in a pharmacy professional program. Am J Pharm Educ. 2005;69(3):Article 43.

6. McCall KL, Allen DD, Fike DS. Predictors of academic success in a doctor of pharmacy program. Am J Pharm Edu. 2006;70(5):Article 106. 7. Schauner S, Hardinger KL, Graham MR, Garavalia L. Admission variables predictive of academic struggle in a PharmD program. Am J Pharm Edu. 2013;77(1):Article 8.

8. Kuncel NR, Credé M, Thomas LL, Klieger DM, Seiler SN, Woo SE. A meta-analysis of the validity of the Pharmacy College Admission Test (PCAT) and grade predictors of pharmacy student performance. Am J Pharm Edu. 2005;69(3):Article 51.

9. Thomas MC, Draugalis JR. Utility of the pharmacy college admission test (PCAT): implications for admissions committees. $\mathrm{Am}$ $J$ Pharm Educ. 2002;66(1):47-51.

10. Unni EJ, Zhang J, Radhakrishnan R, et al. Predictors of academic performance of pharmacy students based on admission criteria in a 3-year pharmacy program. Curr Pharm Teach Learn. 2011;3(3):192-198.
11. Grillo JA, Latif DA, Stolte SK. The relationship between preadmission indicators and basic math skills at a new school of pharmacy. Ann Pharmacother. 2001;35(2):167-172.

12. Latif DA, Grillo JA. Assessing the basic math skills of first-year doctor of pharmacy students. J Pharm Teaching. 2002;9(2):17-25.

13. Latif DA, Grillo JA. The relationship among pharmacy students' basic math scores, traditional preadmission indicators, and performace in pharmaceutical calculations course. $J$ Pharm Teaching. 2002;10(1):17-29.

14. Accreditation Council for Pharmacy Education. Accreditation standards and key elements for the professional program in pharmacy leading to the doctor of pharmacy degree. Standards 2016. https:// www.acpe-accredit.org/pdf/Standards2016FINAL.pdf.

15. Ely R, Gleason JB, Narasimhan B, McCabe A. Family talk about talk: mothers lead the way. Discourse Process. 1995;19(2):201-218. 16. Fogarty G, Cretchley P, Harman C, Ellerton N, Konki N. Validation of a questionnaire to measure mathematics confidence, computer confidence, and attitudes to the use of technology for learning mathematics. Math Ed Res J. 2001;13(2):154-160. 